\title{
Adverse Weather and Commuting Speed
}

\author{
Muhammad Sabir • Jos Van Ommeren • \\ Mark Koetse • Piet Rietveld
}

Published online: 30 March 2010

(C) The Author(s) 2010. This article is published with open access at Springerlink.com

\begin{abstract}
This paper investigates the welfare effect of travelling through congested areas and adverse weather through changes in the speed of individuals' car trips based on the entire commuting trip. Weather measurements are local and time specific (hourly basis). As most commuters travel twice a day between home and work, we are able to employ panel data techniques, which deals with issues related to unobserved heterogeneity and data selection. We find that travelling through congested areas reduces speed by about $7 \%$. For most commuters the welfare effects of adverse weather conditions are negative but small. However, the commuters' welfare costs due to rain are rather substantial during the evening peak in congested areas (and up to $12 \%$ of the overall commuting costs).
\end{abstract}

Keywords Weather $\cdot$ Car commuting trips $\cdot$ Speed $\cdot$ Travel time $\cdot$ Empirical analysis

\section{Introduction}

In the current paper, we will introduce a number of methodological improvements in the econometric analysis of congestion, weather conditions and travel speed. The econometric approach will be applied to car commuters in the Netherlands with an emphasis on the effect of weather on speed. We are particularly interested whether adverse weather conditions reduce welfare of transport users by a reduction in the speed.

\footnotetext{
M. Sabir $(\bowtie) \cdot J$. Van Ommeren $\cdot$ M. Koetse $\cdot$ P. Rietveld Department of Spatial Economics, VU University Amsterdam, De Boelelaan 1105, 1081 HV Amsterdam, The Netherlands

e-mail: msabir@feweb.vu.nl

J. Van Ommeren • P. Rietveld

Tinbergen Institute, Amsterdam, The Netherlands
} 
The effects of weather on speed are clearly relevant for the theme of accessibility, being a measure for the potential of spatial interaction for individuals, firms or other organisations. Most indicators of accessibility are based on the concept of generalised costs, defined as the weighted sum of monetary costs, travel time and possibly other types of costs. For an analysis of accessibility it is therefore essential that appropriate measures are available for travel speed under various conditions. The contribution of the present paper is that it focuses on the impact of weather on travel time, being one of the components of generalised costs.

Most of the literature available on the effects of weather on road transport focuses on traffic accidents and traffic speed (see Koetse and Rietveld 2009, for an overview of the empirical literature). Most of the evidence shows an increasing effect of precipitation on the frequency of accidents, the impact on accident severity appears to be not as pronounced.

Similarly, some studies analyse the impact of weather on traffic speed. For instance, Maze et al. (2006) use a dataset including 4 years of traffic data from the freeway system in the Minneapolis/St. Paul metropolitan area and weather data from three weather stations nearby the freeway network. They show that adverse weather causes clear reductions in traffic speed; up to $6 \%$ for rain, up to $13 \%$ for snow, and up to $12 \%$ for reduced visibility. Similarly, Ibrahim and Hall (1994) analyse the effects of adverse weather on the speed-flow and flow-occupancy relationships for Canadian travellers (see also Brilon and Ponzlet 1996; Hall and Barrow 1988). They find a small but statistically significant effect of light rain and light snow on the free-flow speed. The effects of heavy rain and heavy snow are much larger, causing a reduction in the free-flow speed of 5-10 km/hour and 38$50 \mathrm{~km} /$ hour, respectively.

We offer a number of methodological improvements. First, in the literature it is common to focus on traffic speed/reliability measured for a specific segment of a road typically one hundred meters (see, for example, Ibrahim and Hall 1994, in the context of weather). This implies that only a small part of a whole trip is analysed. This approach is less insightful because the traveller utility and therefore the welfare effects of weather depend on the total travel time, so interpretation of results for a specific road segment requires assumptions of changes in speed for other parts of the trip. To address this issue, our observations are at the trip level, implying that we focus on the average speed of the whole trip instead of only part of the trip.

Second, we focus on commuting, because, in general, daily variation in demand for employment and therefore daily variation in demand for commuting hardly depends on weather conditions. The welfare loss associated with a reduction in derived demand is therefore negligible, implying we can focus on the welfare effect of transport users. This most probably does not hold for trips related to other activities, for example, demand for recreational and leisure trips is likely negatively affected by adverse weather conditions.

Third, we apply panel data techniques using variation of car commuting trips within the day. We use local weather data measured on an hourly basis, which allows us to use daily variation in weather (previous studies tend to use the average weather per day). One of the main methodological advantages of focusing on commuting trips is that it allows one to apply panel techniques as for most commuters two trips on the same day are observed under different weather circumstances. This is relevant 
as it allows us to deal with potentially important issues related to unobserved heterogeneity and data selection. ${ }^{1}$

In the Netherlands, almost a quarter of commuters use the bicycle. ${ }^{2}$ Welfare effects of adverse weather for bicycle users are not so much caused by delay in trips, but more strongly by the inconvenience of adverse weather itself, which is motivation to focuses exclusively on car commuters. The main objective of the current paper is therefore, to analyse welfare effects of adverse weather associated with changes in speed of car commuting trips. In this paper, we will largely ignore the possible welfare effects of adverse weather through changes in travel time reliability. We leave this issue for further research.

The remainder of this paper is organised as follows. Section 2 discusses the empirical model and the econometric methodology to derive welfare effects of weather through changes in commuting speed. Section 3 discusses the data as well as the explanatory variables included in the model. Section 4 provides the empirical results and discusses the welfare effects of adverse weather conditions for the Netherlands. Finally, Section 5 concludes.

\section{Theory and estimation method}

\subsection{Theoretical background}

Our empirical analysis is based on standard micro-economic theory (e.g. Van Ommeren and Dargay 2006; Fosgerau 2005). Let us assume that the traveller's utility is a concave function of speed and that the travel cost function is a convex function of speed. It can then be shown, quite intuitively, that the optimal speed is chosen such that the marginal benefits of speed (a reduction in travel time given the distance) equals the marginal costs of speed. Given the assumption that the monetary costs are a power function of speed, it can be shown that the double-log model is the preferred statistical model.

Van Ommeren and Dargay (2006) show then that the marginal effect of an exogenous environmental characteristic, such as weather, on the logarithm of speed can be interpreted as the marginal effect of this characteristic on the logarithm of the commuter's total commuting costs (the sum of travel time costs and any other costs that vary with speed). So, it is meaningful to estimate the welfare consequences of the weather conditions using loss in travel time. For our empirical analyses we will use the following logarithmic specification, which is in line with the theoretical considerations above:

$$
\log \left(S_{i t d}\right)=\beta_{0}+\beta_{1} W_{i t d}+\beta_{2} \log \left(D_{i t d}\right)+\beta_{3} \log \left(y_{i}\right)+\beta_{4} X_{i}+\beta_{5} F_{t d}+\xi_{i t d}
$$

where subscript $i$ represents individuals, $t$ represents hour of departure and $d$ represents day of the year. Furthermore, $S$ is speed, $W$ is a vector of individual-specific time-

\footnotetext{
${ }^{1}$ Given individual fixed effects, self-selection bias is reduced because one includes a constant for each commuter and therefore controls for individual preferences.

${ }^{2}$ In the dataset used in this study the commuting shares of the different transport modes are $56 \%$ for car, $23 \%$ for bicycle, $14 \%$ for public transport, $4 \%$ for walking and $3 \%$ for other modes.
} 
varying variables (including weather variables), $D$ denotes the distance travelled, $y$ is the income of individuals, $X$ is a vector of individual variables (including gender, age, etc), and $F$ refers to time-specific characteristics such as degree of urbanisation, hour of travel, day of the year and seasonal variation. Finally, the $\beta$ 's are parameters to be estimated by the model and $\xi$ denotes an unobserved error term.

\subsection{Assumptions regarding conditions of error terms}

In order to analyse the impact of road conditions such as weather on the speed of commuting trips we employed fixed effects techniques. Individual specific fixed effects allow us to control for unobserved differences in preferences among individuals and other unobserved features of individuals (such as the exact location of the individual). These unobserved features are correlated with weather variables. For example, in the western part of the Netherlands, weather tends to be warmer and wetter in the winter than in the rest of the Netherlands. The western part of the Netherlands is also the most congested part, so not controlling for residence location may cause spurious correlation between weather and speed. Furthermore, the interaction of weather with other explanatory variables (such as the presence of congestion in the individual-specific region of residence) is likely correlated with unobserved individual-specific variables. For example, it is plausible that commuters who are more likely to be affected by congested roads (independent of weather conditions) have a lower speed on average.

For the same reasons as discussed above it may be relevant to control for dayspecific and hour-specific fixed effects. For instance, it is plausible that all commuters are affected by a common factor on the same day (apart from weather), which is correlated with weather (for example, summer holidays reduce traffic). Similarly, it is plausible that all commuters are affected by a common factor during the same hours, which is correlated with weather patterns (for example, temperature tends to be higher during the day than during the evening rush hour). Ultimately, we estimate fixed effects panel data models with day-specific, individual-specific and hour-specific effects. Fixed effects models include a dummy variable for each observation in the same group (where a group refers to either an individual, a day or an hour). Note that some commuters have two different distances even when using the same day, which allows us to identify the effect of distance using individual fixed-effects.

\section{Data and model specification}

The data used in this paper are taken from two sources. We make use of the National Transport Survey provided by Statistics Netherlands for 1996. Over the course of an entire year, more than 150,000 individuals were asked to fill out a questionnaire containing 77 different questions about their travel behaviour (all trips) during a single day and about important individual and household characteristics. The dataset contains more than 628,000 reported trips. For most commuters we observe two commuting trips a day. For some commuters we only observe one commuting trip (predominantly due to underreporting of one of the trips) while for others we 
observe more than two commuting trips (for example, for workers with multiple jobs or who go home for lunch).

The second data source is a weather database available from the Royal Netherlands Meteorological Institute (KNMI) for 1996. It contains weather conditions on an hourly basis for 32 weather stations spread all over the Netherlands. We use the weather conditions from the weather stations which are nearest to commuters' places of departure (in almost all cases). The average distance to a weather station is about 12 to $13 \mathrm{~km}$, which means that our measurement of weather conditions is more local than is common in the literature. This is potentially important, as the incidence of rain, which as we will see is a weather determinant of commuting speed, is known to be local especially during the summer months. The weather conditions refer to temperature (we distinguish between temperatures above and below zero), wind speed (wind strengths exceeding 6 Beaufort), rain and falling snow. Falling snow is measured as the interaction effect of rain and temperatures equal to or below $0^{\circ} \mathrm{C}$. Note that our snow measure only captures falling snow and not the level of snow on roads, which may be the more relevant variable in the current context. Hence, we have for each commuting trip the local weather conditions of the hour in which the trip took place. Nevertheless, as precipitation is much more localized and variation of precipitation within $1 \mathrm{~h}$ is much higher than captured by our measure, it is plausible that due to (random) measurement error, our weather effects are downward biased.

As already mentioned in the introduction, we select only car commuting trips for our analyses. This has a number of economic and statistical reasons. First, and most importantly, we select commuting trips because the demand for commuting is derived from the demand for labour, which does not directly depend on weather, whereas the derived demand for other trips (in particular, leisure trips) are affected by daily variation in weather conditions. Hence, for commuting trips, interpretation of the welfare effect of weather is more straightforward. Second, commuting distance can be instrumented avoiding problems with the endogeneity of distance to speed, whereas this may be more difficult for other travel purposes (Van Ommeren and Dargay 2006). Third, we select car trips because for other modes, and in particular cycling, which is the main alternative for car use in the Netherlands, the welfare of commuting is directly affected by the weather and not so much through its effects on traffic speed. A possible critique on our sample selection is that it may generate biased estimates (for example, Wooldridge 2003). However, by including individual specific fixed-effects, one also controls for individual specific selection effects that may occur since we have a selected sample of car commuters because the individual specific dummies included control for unobserved individual preferences for speed.

Given these restrictions, our sample contains 42,534 car commuting trips made by 17,248 commuters. Average trip distance is $20 \mathrm{~km}$, average speed is $43.9 \mathrm{~km} / \mathrm{h}$ and average commuting time is $24.5 \mathrm{~min}$. The means and standard deviations of other explanatory variables are provided in Appendix A. Most explanatory variables included in the model are self-explanatory and are included to control for differences in 'demand' for speed (for example, gender) as well as for characteristics that effect the cost of speed (for example, degree of urbanisation). Some variables need some additional explanation. Van Ommeren and Dargay (2006) use the wage rate in the specification of their theoretical speed model but, because of lack of data on wages, 
they use individual income for their empirical analysis. We will also use individual income instead of the wage rate for the same reason. Further, we estimate the effect of rush hours (morning and evening rush hours) which is useful to capture general congestion effects. In a separate analysis, we distinguish between morning and evening rush hours. The results are almost identical and can be provided on request. Furthermore, adverse weather may have stronger effects on speed during rush hours, due to increased demand for car travel or due to an increase in the minimum distance between cars, which is necessary for safety reasons. The interaction of (morning and evening) rush hours and rain are therefore included in the model. We include interaction effects for the rain variable but not for temperature and wind because the main effects of these weather variables are small. In addition, inclusion of more interaction effects makes interpretation of the effects cumbersome.

We estimate the effect of travelling on above average congested routes by distinguishing trips longer than $10 \mathrm{~km}$ that are directed towards or originate from one of the four major cities in the Randstad in the morning and evening peak. The Randstad consists of a ring of the four largest cities in the Netherlands (Amsterdam, Utrecht, Rotterdam, the Hague) and their surrounding areas. The population of the Randstad is over seven million inhabitants, which is almost $50 \%$ of the total population of the country. These cities contain the main centres of employment and business activities, so in the morning, congestion occurs on roads towards the four cities while in the afternoon it occurs on roads from these four cities.

Specifically, a morning peak congestion dummy is equal to one when a trip is longer than $10 \mathrm{~km}$, is directed towards one of the four major cities, and took place between 07.00 and 09.00 in the morning. An evening peak dummy is equal to one when a trip is longer than $10 \mathrm{~km}$, originates from one of the four major cities, and took place between 16.00 and 18.00 in the evening. Since most traffic jams occur at highways near the major cities the model should pick up the effects of congestion on speed. Furthermore, we interact the morning and evening peak congestion variables with a rain dummy in order to test whether rain has a stronger impact on speed on already congested routes than during free-flow. We select the trips longer than $10 \mathrm{~km}$ to increase the probability that a trip takes place partly on highways. In order to control for carpooling effects, we control for the number of people in the vehicle (Rietveld et al. 1999). Seasonal effects are captured by seasonal dummy variables.

\section{Results}

\subsection{Speed}

The results of the various model estimations are provided in Table 1. In general, the results are robust with respect to the type of model estimated. The signs and magnitudes of the effects are comparable across the models with few exceptions.

The results suggest that adverse weather conditions generally have a rather limited impact on car commuting speed except for falling snow and strong wind given the hour fixed effects specification. Extreme wind strengths appear to have a negative effect on speed of approximately $2 \%$ and falling snow of about $7 \%$. There appears to be no effect of rain, suggesting that free-flow speed is not affected by rain. Therefore, although there 
Table 1 Analysis of logarithm of speed of car commuting trips

\begin{tabular}{|c|c|c|c|c|c|c|}
\hline & \multirow{2}{*}{\multicolumn{2}{|c|}{$\begin{array}{l}\text { Day specific } \\
\text { Fixed effects }\end{array}$}} & \multirow{2}{*}{\multicolumn{2}{|c|}{$\begin{array}{l}\text { Individual specific } \\
\text { Fixed effects }\end{array}$}} & \multirow{2}{*}{\multicolumn{2}{|c|}{$\begin{array}{l}\text { Hour specific } \\
\text { Fixed effects }\end{array}$}} \\
\hline & & & & & & \\
\hline & Coeff. & S.E. & Coeff. & S.E. & Coeff. & S.E. \\
\hline \multicolumn{7}{|l|}{ Weather variables } \\
\hline Wind strength $>6$ Beaufort & -.022 & .014 & -.005 & .018 & -.026 & .013 \\
\hline Temperature $<0^{\circ} \mathrm{C}$ & -.002 & .011 & .018 & .012 & .006 & .007 \\
\hline Rain & .002 & .012 & .002 & .013 & -.001 & .007 \\
\hline Falling snow & -.057 & .036 & .012 & .043 & -.075 & .033 \\
\hline Rush hour $\times$ rain & -.011 & .014 & -.001 & .015 & - & - \\
\hline Congestion morning peak $\times$ rain & -.030 & .042 & -.026 & .048 & -.037 & .042 \\
\hline Congestion evening peak $\times$ rain & -.068 & .042 & -.122 & .046 & -.068 & .041 \\
\hline \multicolumn{7}{|l|}{ Other explanatory variables } \\
\hline Rush hour & -.042 & .004 & -.034 & .005 & - & - \\
\hline Congestion morning peak & -.031 & .012 & -.076 & .017 & -.041 & .013 \\
\hline Congestion evening peak & -.042 & .013 & -.069 & .017 & -.035 & .013 \\
\hline Carpooling & -.071 & .006 & -.054 & .010 & -.068 & .006 \\
\hline Income (Ln) & .000 & .004 & - & - & .002 & .004 \\
\hline Distance travelled (Ln) & .406 & .002 & .436 & .003 & .412 & .002 \\
\hline Very urbanised & -.167 & .009 & - & - & -.167 & .009 \\
\hline Urbanised & -.141 & .006 & - & - & -.142 & .006 \\
\hline Moderately urbanised & -.100 & .006 & - & - & -.102 & .006 \\
\hline Little urbanised & -.034 & .005 & - & - & -.036 & .005 \\
\hline Gender (Males) & .032 & .005 & - & - & .039 & .005 \\
\hline Age between 30 and 40 years & -.004 & .005 & - & - & -.008 & .005 \\
\hline Age between 40 and 65 years & -.032 & .005 & - & - & -.034 & .005 \\
\hline Age greater than 65 years & -.138 & .027 & - & - & -.155 & .027 \\
\hline Weekends & - & - & - & - & .052 & .007 \\
\hline Summer & - & - & - & - & .026 & .006 \\
\hline Autumn & - & - & - & - & -.008 & .005 \\
\hline Winter & - & - & - & - & -.012 & .006 \\
\hline $\mathrm{R}^{2}$ & \multicolumn{2}{|l|}{.581} & \multicolumn{2}{|l|}{.883} & \multicolumn{2}{|l|}{.576} \\
\hline Number of observations & \multicolumn{2}{|l|}{42,435} & \multicolumn{2}{|l|}{42,435} & \multicolumn{2}{|l|}{42,435} \\
\hline Number of groups & \multicolumn{2}{|l|}{366} & \multicolumn{2}{|l|}{17,248} & \multicolumn{2}{|l|}{24} \\
\hline
\end{tabular}

Bold coefficients are statistically significant at 5\%, italic coefficients are statistically significant at $10 \%$ The reference categories for temperature, urbanisation, age, and seasonal variables, are temperature $>0{ }^{\circ} \mathrm{C}$, rural, age between 18 and 30 years, and spring, respectively

appear to be some negative welfare consequences of adverse weather conditions, these seem to be close to negligible except for snow and maybe extreme winds. To estimate these welfare costs we focus on the average commuter. For this commuter the average commuting time is $0.41 \mathrm{~h}$ (see Appendix A). 
To estimate the welfare effect of weather through changes in traffic speed, we use information on the average value of travel time (see, for example, Small and Verhoef 2007). Based on a meta-analysis of 56 value-of-time estimates from 14 different countries, Waters (1996) finds an average ratio of value of time equal to $48 \%$ of gross wage rate and a median ratio of $42 \%$ for commuting trips made by automobile. In another review, Wardman (1998) finds similar values. In the Netherlands, gross hourly wage rates for car commuters are about $€ 16$, suggesting a value of time of about $€ 8$ per hour. This figure has been derived from the Dutch National Household Survey including employees who commute by car. Therefore, the welfare effect of falling snow through loss in travel time is around $€ 0.23(.41 \times .07 \times € 8)$ per commuting trip. For extreme winds the welfare loss is around $€ 0.07(.41 \times .07 \times € 8)$ per commuting trip. Since both types of weather conditions rarely occur, the overall welfare costs are negligible.

With respect to the impact of other variables, speed is reduced by around $4 \%$ during rush hours. Trips made in the morning and evening peaks and on congested routes are also substantially slower. Congestion in the morning and evening peak both cause a speed reduction of at least $7 \%$ compared to non-peak times. The congestion related welfare losses amount to $€ 0.23(.41 \times .07 \times € 8)$ per commuting trip in both morning peak and evening peak. Carpooling also strongly reduces trip speed by about $7 \%$, the likely underlying causes being waiting times and detours made to pick up passengers. In contrast to Fosgerau (2005), who also focuses on car commuting trips, we find no statistically significant effect of income on speed. Furthermore, we find that the distance elasticity is around .40 to .44 (in line with Van Ommeren and Dargay 2006). The degree of urbanisation strongly reduces trip speed, with around $17 \%$ speed reduction in very urbanised areas (see also Van Ommeren and Dargay 2006). This result is plausible because trips made in urban areas experience more congestion and encounter more road signals and crossing points compared to trips made in rural areas. Some other results are that older people drive slower, that trips made during weekends are faster than trips made on working days, and that male commuters drive slightly faster than female commuters. The latter is consistent with the literature (see, e.g., Rietveld et al. 1999; Van Ommeren and Dargay 2006).

Finally, the interactions of rain show interesting results. The effect of rain on the speed of trips made during rush hour is negative but small and statistically insignificant. This finding is in line with our previous finding that rain has relatively limited negative welfare consequences. However, although rain during the morning peak on congested routes appears to have any effect, there does appear to be a substantial negative impact of rain on the speed of trips made on congested routes during the evening peak. The difference between these estimates for morning and evening peak times may be entirely due to random variation but may also be due to additional congestion caused by adverse weather before the evening peak. The additional impact of rain on speed reduction for evening trips ranges from 7 to $12 \%$. Hence, this suggests that the welfare loss of rain when commuters face congested roads turns out to be substantial and between 7 and $12 \%$ of total commuting costs. Note that the average commuting time of trips in the evening peak on congested routes is $.51 \mathrm{~h}$ (see Appendix A), which means that the additional welfare loss through increases in travel time due to rain is around $€ 0.50(.51 \times .12 \times € 8)$ per commuting trip in the evening peak on congested routes. 
It may be argued that the distance variable included in the model is endogenous since the distance travelled may depend on speed (Van Ommeren and Dargay 2006). In order to address this problem the model has been re-estimated by instrumental variables (IV), using the education of commuters as an instrument of distance. The results are almost identical, so the IV estimates are not reported here. We have also investigated other weather variables (such as sunlight) but did not find any effect. Furthermore, our results are robust by selecting sub-samples (such as the selection of commuters that are observed exactly twice). Adverse weather may not only affect average speed but also speed variation. In the log linear model the estimated standard error of residuals has a direct effect on estimated expected traffic speed, which implies that adverse weather may also have an effect through the standard error of residuals. In order to analyse whether this is the case we allow the variance of the error term to vary with weather and several other variables in the model with individual-specific fixed effects. This exercise shows that adverse weather has only a small and statistically insignificant effect on the standard error of residuals. Consequently, our estimates are robust with respect to the specification of the variance.

\subsection{Reliability}

One may argue that our estimates of the effect of bad weather on welfare is an underestimate of the real welfare effect, because we have ignored the welfare effects of increased unreliability and arrival times at work due to bad weather. To test for the presence of unreliability, we have estimated a linear speed model with heteroskedasticity due to adverse weather. These analyses show that rain during peak hour strongly increases the variance, but this effect largely disappears for the fixed-effects model. These results suggest that adverse weather increases betweenday unreliability but does not increase within-day unreliability. We have attempted to estimate the welfare losses of increased unreliability, making use of the conceptual framework of Small (1982). According to this model, increased unreliability in travel times implies that workers leave earlier from home in order to be at work in time. To address this issue, we have estimated the effect of the weather variables on the morning departure time of the car drivers (after six o'clock and before 12 o'clock). Hence, the dependent variable is a duration variable. The explanatory variables included are the individual (including commuting distance) and household variables (including the urbanisation degree of the region of residence) that were included in the previous analyses, as well as the weather variables which are allowed to vary by hour. Clearly, the hazard rate of departing time varies strongly by hour. We have therefore estimated semiparametric duration models using a partial likelihood approach, as these models do not require any parametric assumptions on the effect of hour time on the departure time (see Lancaster 1990). Our estimates do not show any evidence that bad weather makes people depart earlier for work. In fact, we even find a small positive effect of snow on the departure time (workers leave about five minutes later). This finding is consistent with the studies by Arnott et al. (1991, 1999) as well as De Palma and Lindsey (1998), in which stochastic bottleneck models are analysed. 


\section{Conclusions}

In this paper we analyse the effects of weather on the speed of car commuting trips for the Netherlands. We use micro data at the trip level based on the national transportation survey and detailed local time-specific weather conditions for the Netherlands for the year 1996. One novelty of the approach used in the current paper is that our observations are at the trip level, implying that we focus on the average speed of the whole trip instead of only part of the trip, which is the standard approach in the literature. We estimate panel data models with a range of fixed effects. We use a large number of explanatory variables in our models such as distance travelled, age, gender, degree of urbanisation, income, and hour of the day. Our main interest is in the effect of weather variables such as temperature, rain, snow, and wind strength. We also include interaction effects of the weather variables with congestion specific variables. We have taken the potential endogeneity of distance into account.

In general, the results are robust with respect to model specification and type of model estimated. Snow is the only weather condition that clearly reduces trip speed, the reduction being around $7 \%$. However, since snowfall is rare the associated welfare loss in The Netherlands is limited. Interesting is the speed reduction in the morning and evening peaks on congested routes, which is around $7 \%$. The associated welfare loss through increases in travel time is around $€ .23$ per commuting trip. These effects are exacerbated by rain, which has a strong negative effect on trip speed on congested routes, especially during the evening peak. The welfare effect of rain for these trips ranges between $9 \%$ and $12 \%$ of total commuting costs and amounts to at least $€ .50$ per commuting trip.

By our analysis of weather dependence of speed we provide an enrichment of the accessibility concept. Accessibility depends among others on travel times and given the impact of weather on travel times, we find that weather is one of the determinants of accessibility.

Acknowledgements We would like to thank Erik Verhoef for useful comments and Lennard Horstink (KNMI) for providing the weather data. This research has been supported through Nuffic, the Higher Education Commission of Pakistan, and the 'Climate Changes Spatial Planning' research programme. Jos Van Ommeren would like to thank the Frisch Centre, Oslo Norway for its hospitality and the Netherlands Organisation for Scientific Research (NWO) for funding.

Open Access This article is distributed under the terms of the Creative Commons Attribution Noncommercial License which permits any noncommercial use, distribution, and reproduction in any medium, provided the original author(s) and source are credited.

\section{Appendix A}

Table 2 Descriptive statistics of variables used in the empirical model $(N=42,534)$

\begin{tabular}{lrr}
\hline & Mean & S.D. \\
\hline Continuous variables & & 31.9 \\
Speed (km/hour) & 43.9 & 5.04 \\
Income (in 000's Euro) & 14.2 & .54 \\
Income (Ln) & 2.54 &
\end{tabular}


Table 2 (continued)

\begin{tabular}{|c|c|c|}
\hline & Mean & S.D. \\
\hline Distance (in km) & 20.1 & 25.5 \\
\hline Distance (Ln) & 2.41 & 1.14 \\
\hline Commuting time (in hours) & .41 & .38 \\
\hline Commuting time non-congested roads (in hours) & .40 & .38 \\
\hline Commuting time congestion morning peak (in hours) & .45 & .35 \\
\hline Commuting time congestion evening peak (in hours) & .51 & .37 \\
\hline \multicolumn{3}{|l|}{ Dummy variables } \\
\hline Strong wind & .024 & \\
\hline Temperature $<=0^{\circ} \mathrm{C}$ & .166 & \\
\hline Rain & .091 & \\
\hline Falling snow & .004 & \\
\hline Rush hour & .603 & \\
\hline Rush hour $\times$ rain & .055 & \\
\hline Carpooling & .114 & \\
\hline Males & .699 & \\
\hline Age between 18 and 30 years & .242 & \\
\hline Age between 30 and 40 years & .299 & \\
\hline Age between 40 and 65 years & .448 & \\
\hline Age greater than 65 years & .005 & \\
\hline Very urbanised & .058 & \\
\hline Urbanised & .190 & \\
\hline Moderately urbanised & .224 & \\
\hline Little urbanised & .277 & \\
\hline Rural & .251 & \\
\hline Weekends & .077 & \\
\hline Spring & .262 & \\
\hline Summer & .215 & \\
\hline Autumn & .253 & \\
\hline Winter & .270 & \\
\hline Congestion morning peak & .045 & \\
\hline Congestion morning peak $\times$ rain & .004 & \\
\hline Congestion evening peak & .039 & \\
\hline Congestion evening peak $\times$ rain & .003 & \\
\hline
\end{tabular}

\section{References}

Arnott R, De Palma A, Lindsey R (1991) Does providing information to drivers reduce traffic congestion? Transp Res Part A 25:309-318

Arnott R, De Palma A, Lindsey R (1999) Information and time-of-usage decisions in the bottleneck model with stochastic capacity and demand. Eur Econ Rev 43(3):525-548

Brilon W, Ponzlet M (1996) Variability of speed-flow relationships on German autobahns. Transp Res Rec 1555:91-98

De Palma A, Lindsey R (1998) Information and usage of congestible facilities under different pricing regimes. Can J Econ 31(3):666-692 
Fosgerau M (2005) Speed and income. J Transp Econ Policy 39:225-240

Hall FL, Barrow D (1988) Effect of weather on the relationship between flow and occupancy on freeways. Transp Res Rec 1194:55-63

Ibrahim AT, Hall FL (1994) Effect of adverse weather conditions on speed-flow-occupancy relationships. Transp Res Rec 1457:184-191

Koetse MJ, Rietveld P (2009) The impact of climate change and weather on transport: an overview of empirical findings. Transp Res Part D 14(3):205-221

Lancaster T (1990) The econometric analysis of transition data. Cambridge University Press, Cambridge

Maze TH, Agarwal M, Burchett G (2006) Whether weather matters to traffic demand, traffic safety, and traffic operations and flow. Transp Res Rec 1948:170-176

Rietveld P, Zwart B, Van Wee B, Van den Hoorn T (1999) On the relationship between travel time and travel distance of commuters: reported versus network data in the Netherlands. Ann Reg Sci 33:269287

Small AK (1982) The scheduling of consumer activities: work trips. Am Econ Rev 72:467-479

Small AK, Verhoef ET (2007) The economics of urban transportation, 2nd edn. Routledge, London

Van Ommeren J, Dargay J (2006) The optimal choice of commuting speed: consequences for commuting time, distance and costs. J Transp Econ Policy 40:279-296

Wardman M (1998) The value of travel time: a review of British evidence. J Transp Econ Policy 32:285316

Waters WGI (1996) Values of travel time savings in road transport project evaluation, word transport research, Proceedings of 7th World Conference on Transport Research, vol 3. Pergamon, Oxford

Wooldridge JM (2003) Introductory econometrics: a modern approach, 2nd edn. South-Western College Publishing, Ohio 